\title{
Neutral and Ion Chemistry and Solar Fluxes*
}

\author{
Marsha R. TORR \\ Department of Physics, Utah State University \\ Logan, Utah, U.S.A.
}

(Received November 2, 1982)

\begin{abstract}
In this report we review significant developments in the areas of neutral and ion chemistry in the thermosphere and in solar flux measurements since the 1979 IAGA meeting. Considerable progress has been made and this report is by no means complete. Several very long standing problems have been solved, and some major issues have been opened in areas which were considered fairly well resolved.
\end{abstract}

\section{Introduction}

During the half-decade prior to the 1979 IAGA meeting in Canberra, we saw an explosion in the thermospheric chemistry database. This was largely due to the Atmosphere Explorer satellite program, but was greatly enhanced by parallel ongoing and stimulated laboratory work. At the time of the Canberra meeting, we had seen such progress in the quantification of the ion and neutral chemistry and the solar fluxes shortward of $1,027 \AA$, that it may well have been concluded by many that the thermospheric photochemistry was essentially a closed book. It may therefore come as a surprise to those with this view, that the advances in understanding over the past eighteen months have been of major significance. Some fundamental problems have been uncovered in areas which were considered to be relatively well understood. Some longstanding problems have been resolved. We have continued to see a most beneficial interaction between aeronomic work and laboratory work, with the aeronomic work in some cases revealing problems in the laboratory measurements where the configuration is not always applicable to the atmosphere, and the laboratory work in other cases revealing missing processes in the aeronomic determinations.

We are by no means at the end of the trail. The remaining problems are interesting and are going to require very careful unravelling.

In the twenty minutes available to me, it is quite impossible to do justice to the volume of new work that has been done in the broad area of neutral and ion chemistry and solar fluxes since the last IAGA meeting in 1979. Only some of the highlights will be touched on. In addition, we will restrict the report for this meeting to progress in the thermosphere.

*The report (Topic II-2) to the IAGA Assembly, Edinburgh, 1981. 


\section{Areas of Significant Progress}

In this section, we will briefly discuss half a dozen areas in the thermospheric photochemistry and solar fluxes where significant advances have been made. There are several other examples which could have been equally well used.

\subsection{Thermospheric photochemical scheme}

In Fig. 1 we show a schematic illustration of the major processes in the thermospheric chemistry scheme. At the time of the 1979 IAGA meeting this scheme was believed to be well quantified. By selecting data taken under specific conditions in order to enhance a particular process, most of the individual branches had been studied separately. Then using the Atmosphere Explorer database which spanned a wide variety of conditions (seasonal, diurnal, magnetic storm), the model was found to consistantly reproduce the mean variations in the data. All of the nodal points in the scheme shown in Fig. 1 were measured by the Atmosphere Explorer complement of instruments with one notable exception, $\mathrm{O}^{+}\left({ }^{2} \mathrm{D}\right)$. In retrospect, this was a serious oversight, as this species plays a pivotal role in determining the atomic to molecular ion ratio.

Developments in $F$-region photochemistry over the past two years, focussed largely on the

$$
\mathrm{O}^{+}\left({ }^{2} \mathrm{D}\right)+\mathrm{N}_{2}-\mathrm{N}_{2}^{+}+\mathrm{O}
$$

charge exchange process.

Early measurements by STEBbings et al. (1966), and RUTHERFORD and VROOM

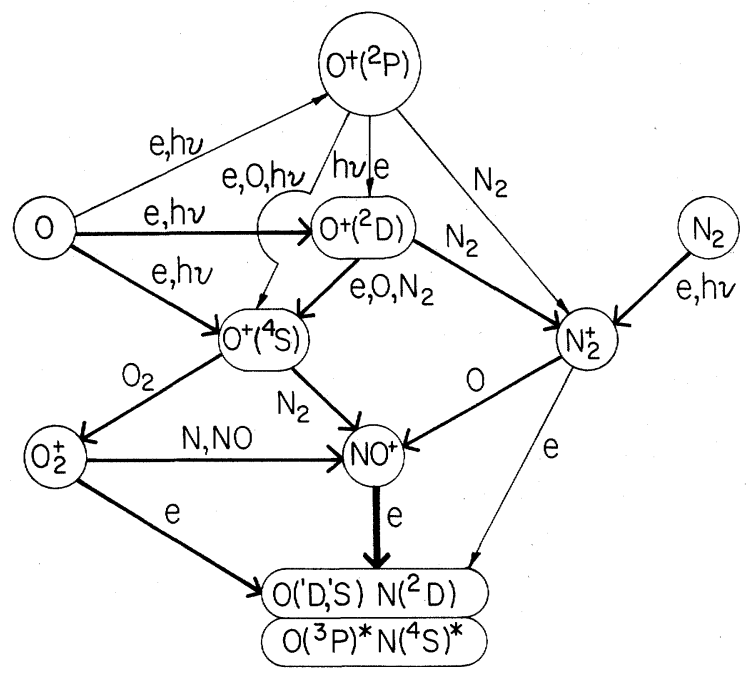

Fig. 1. Thermospheric photochemistry scheme showing major processes identified at the time of the 1979 IAGA meeting. 
$(1971,1974)$, at high ion kinetic energies $(0.5 \mathrm{eV})$ set the rate coefficient for this reaction at approximately $1 \times 10^{-9} \mathrm{~cm}^{3} \mathrm{sec}^{-1}$. A subsequent laboratory measurement by Glosik et al. (1978) found the rate coefficient to be approximately 1 $\times 10^{-10} \mathrm{~cm}^{3} \mathrm{sec}^{-1}$. In 1979 the aeronomical scheme appeared to be in harmony with the lower rate. Subsequently, in the light of the reawakened interest caused by the aeronomical progress, a new laboratory measurement was made by JOHNSEN and BIONDI (1980) who found the rate to be $\sim 8 \times 10^{-10} \mathrm{~cm}^{3} \mathrm{sec}^{-1}$. We were now faced with a situation in which we had a laboratory measurement at high energies of $10^{-9} \mathrm{~cm}^{3} \mathrm{sec}^{-1}$, and two laboratory measurements at thermospheric energies which differed from each other by an order of magnitude. In addition the aeronomy results preferred the lower rate of $10^{-10} \mathrm{~cm}^{3} \mathrm{sec}^{-1}$. Fortunately, at this time, a second laboratory group using a quite different technique, repeated the experiment (RowE et al., 1980) and also obtained $\sim 8 \times 10^{-10} \mathrm{~cm}^{3} \mathrm{sec}^{-1}$.

If this rate is appropriate for the thermosphere, it poses major problems in that it would result in the production of far too much $\mathrm{N}_{2}^{+}$and $\mathrm{NO}^{+}$and too little $\mathrm{O}^{+}\left({ }^{4} \mathrm{~S}\right)$. The channel $\mathrm{O}^{+}\left({ }^{2} \mathrm{D}\right)+\mathrm{e} \rightarrow \mathrm{O}^{+}\left({ }^{4} \mathrm{~S}\right)+\mathrm{e}$ is completely overwhelmed by reaction $(1)$. Thus, within months of arriving at a point where the thermospheric chemistry appeared to be generally well quantified, the very heart of the photochemical scheme was thrown into uncertainty. At this point one could either abandon ship, so to speak, and revert to using any photochemical reaction rate coefficients that would best serve one's theoretical purposes, or take very close stock of the situation and try to interpret the implications. Clearly only those fairly well steeped in the thermospheric chemistry would have the confidence to do the latter, as the large number of processes with their various dependencies can easily appear as a variable maze to the observer.

What is needed is a process that restores the $\mathrm{N}_{2}^{+} / \mathrm{O}^{+}\left({ }^{4} \mathrm{~S}\right)$ balance and closely mimics the $F$-region seasonal behavior produced by the lower $\left(10^{-10} \mathrm{~cm}^{3} \mathrm{sec}^{-1}\right)$ rate coefficient. Such a process is not easy to find as the overall system is too tightly knit when viewed in its entirety. There were only two adjustable parameters. The $\mathrm{O}^{+}\left({ }^{2} \mathrm{D}\right)+\mathrm{N}_{2}$ charge exchange rate and the $\mathrm{N}_{2}^{+}$recombination rate coefficient. With these fixed by laboratory measurements, only the photochemical scheme itself could be questioned.

A search for a major missing process has been undertaken in the past year and the outcome is described by ABDOU et al. (1982, 1983) and TORR et al. (1980). In short, two viable and intriguing processes have been identified which would come into significance under different geophysical conditions to restore the photochemical balance. We can only give the briefest summary here. We have already mentioned above that the large body of the Atmosphere Explorer data indicated a strong preference for a charge exchange rate coefficient for $\mathrm{O}^{+}\left({ }^{2} \mathrm{D}\right)$ with $\mathrm{N}_{2}$ of $10^{-10} \mathrm{~cm}^{3} \mathrm{sec}^{-1}$. After a long search, three or four 'anomalous' orbits of data were found by E. Breig which apparently required a high value for this rate coefficient of $10^{-9} \mathrm{~cm}^{3} \mathrm{sec}^{-1}$. Working with these data to begin with, ABDOU et al. (1982) found that the resonant reaction, which had not been considered previously

$$
\mathrm{O}^{+}\left({ }^{2} \mathrm{D}\right)+\mathrm{N}_{2}\left(\mathrm{X}^{1} \sum_{\mathrm{g}}^{+}\right)_{v=0} \rightleftarrows \mathrm{N}_{2}^{+}\left(\mathrm{X}^{2} \sum_{\mathrm{g}}^{+}\right)_{v=5}+\mathrm{O}\left({ }^{3} \mathrm{P}\right)
$$


partially resolved the problem. When the reverse resonant reaction is included, they found that they were able to explain one of the anomalous orbits. It was further concluded that because of the likely temperature dependence of this process, it becomes significant only in a narrow temperature window. Under these conditions, the photochemical scheme would thus be modified to that shown in Fig. 2.

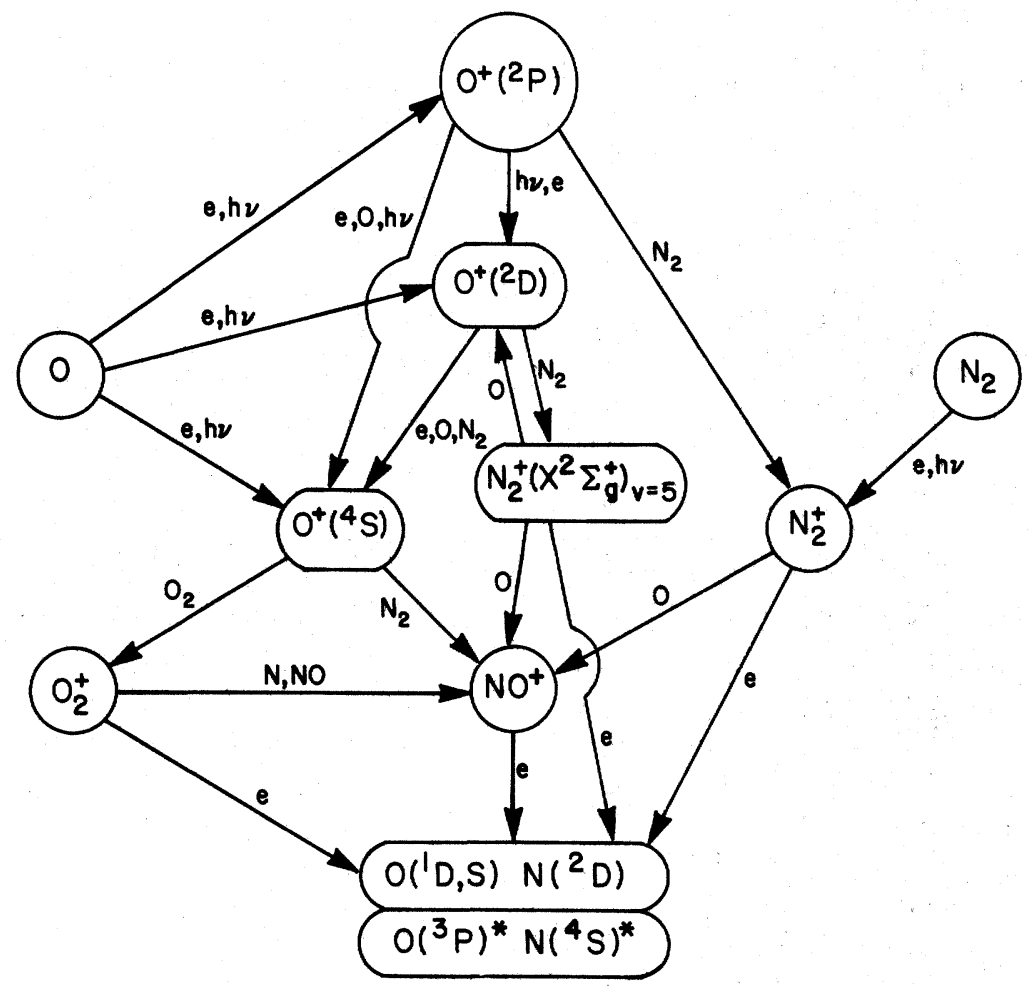

Fig. 2. Thermospheric photochemistry scheme modified to include the resonant back reaction from $\mathrm{N}_{2}^{+}\left(\mathrm{X}^{2} \sum_{\mathrm{g}}^{+}\right)$(from ABdou et al., 1982).

However, even with this process, the database generally representative of the solar minimum mid-latitude thermosphere studied by Atmosphere Explorer is not in harmony with the laboratory results because certain cases were identified for which a low rate coefficient was required when the temperature was such that the resonant condition was not satisfied. TORR et al. (1982) subsequently identified a second similar process which when added to the resonant reactions resulted in a model which would possess all the predictive attributes required by the variability imposed by the conditions spanned by the database. This second process is illustrated in Fig. 3, i.e.

$$
\mathrm{N}_{2}^{+}(\text {vib })+\mathrm{O} \rightarrow \mathrm{O}^{+}\left({ }^{4} \mathrm{~S}\right)+\mathrm{N}_{2}
$$




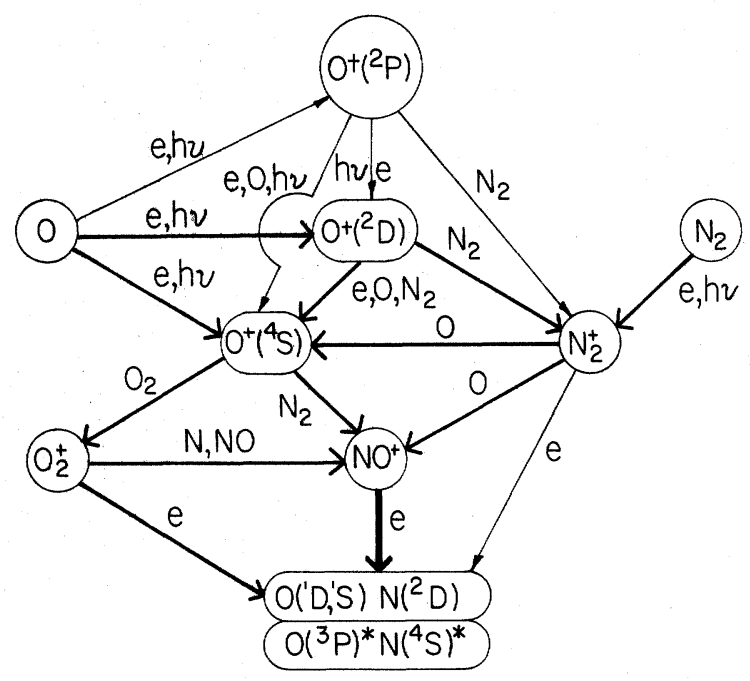

Fig. 3. Thermospheric photochemistry scheme modified to show reaction involving $\mathrm{N}_{2}^{+}$(vib) and 0 (from TORR and TORR, 1982).

The $\mathrm{N}_{2}^{+}$ions in the thermosphere are vibrationally excited by resonance scattering and fluorescence of solar near UV and near IR radiation. Under normal thermospheric conditions, this process converts the excess $\mathrm{N}_{2}^{+}$produced by reaction (1) to $\mathrm{O}^{+}\left({ }^{4} \mathrm{~S}\right)$, thus restoring the photochemical balance if the reaction proceeds at approximately $2 \times 10^{-10} \mathrm{~cm}^{3} \mathrm{sec}^{-1}$ between $250-300 \mathrm{~km}$. This model will, of course, require careful empirical testing for its verification.

\subsection{The metastable state of atomic oxygen, $\mathrm{O}\left({ }^{1} \mathrm{D}\right)$}

One of the longest studied metastable species in the atmosphere is $\mathrm{O}\left({ }^{1} \mathrm{D}\right)$. Prior to $\mathrm{AE}$ it had been generally believed that this species was on the whole well understood. In an high latitude study by RUSCH et al. (1978) a major source of $\mathrm{O}\left({ }^{1} \mathrm{D}\right)$ was found to be missing in the aurora. A likely candidate for this source was identified to be

$$
\mathrm{N}\left({ }^{2} \mathrm{D}\right)+\mathrm{O}_{2} \rightarrow \mathrm{NO}+\mathrm{O}\left({ }^{1} \mathrm{D}\right)
$$

TORR et al. (1981) then identified a similar problem in the dayglow. They found that the same $N\left({ }^{2} \mathrm{D}\right)$ source would solve the problem most satisfactorily. The omission of this source had previously resulted in overestimates of the $\mathrm{O}\left({ }^{1} \mathrm{D}\right)$ component due to photodissociation of $\mathrm{O}_{2}$, or incorrect assumptions regarding the $\mathrm{O}_{2}$ concentration and its diurnal variation. Early ground-based attempts to determine the solar flux in the Schumann-Runge absorption range or the $\mathrm{O}_{2}$ concentration of $\mathrm{O}\left({ }^{1} \mathrm{D}\right)$ from twilight $6,300 \AA$ measurements were not valid in the light of this process.

In a more recent auroral study, LINK et al. (1981) dispute the need for the 
$\mathrm{N}\left({ }^{2} \mathrm{D}\right)$ source. Their database, however, is not sufficiently encompassing to be conclusive and further work is needed in this area.

\subsection{The atomic oxygen metastable, $\mathrm{O}\left({ }^{1} \mathrm{~S}\right)$}

A decade old problem has been that of the $\mathrm{O}\left({ }^{1} \mathrm{~S}\right)$ species. The battle concerning its source mechanism has swung back and forth, as have determinations of the quenching species and the quenching rates. Till very recently conclusions concerning $\mathrm{O}\left({ }^{1} \mathrm{~S}\right)$ have been driven strongly by laboratory measurements and determinations of the quenching rate coefficients. Some very nice progress in this area has been made since the IAGA meeting in Canberra by THOMAs (1981) on aeronomical grounds. His conclusions are based on rocket measurements of the $\mathrm{O}\left({ }^{1} \mathrm{~S}\right)$ and Herzberg I emissions, as well as the atomic oxygen concentration, and amplified by some additional detective work using clues from the Venus atmosphere.

From shape considerations THOMAS (1981) concluded that the Chapman mechanism could not explain the observed layer without the assumption of an unrealistic temperature profile. This is illustrated in Fig. 5.

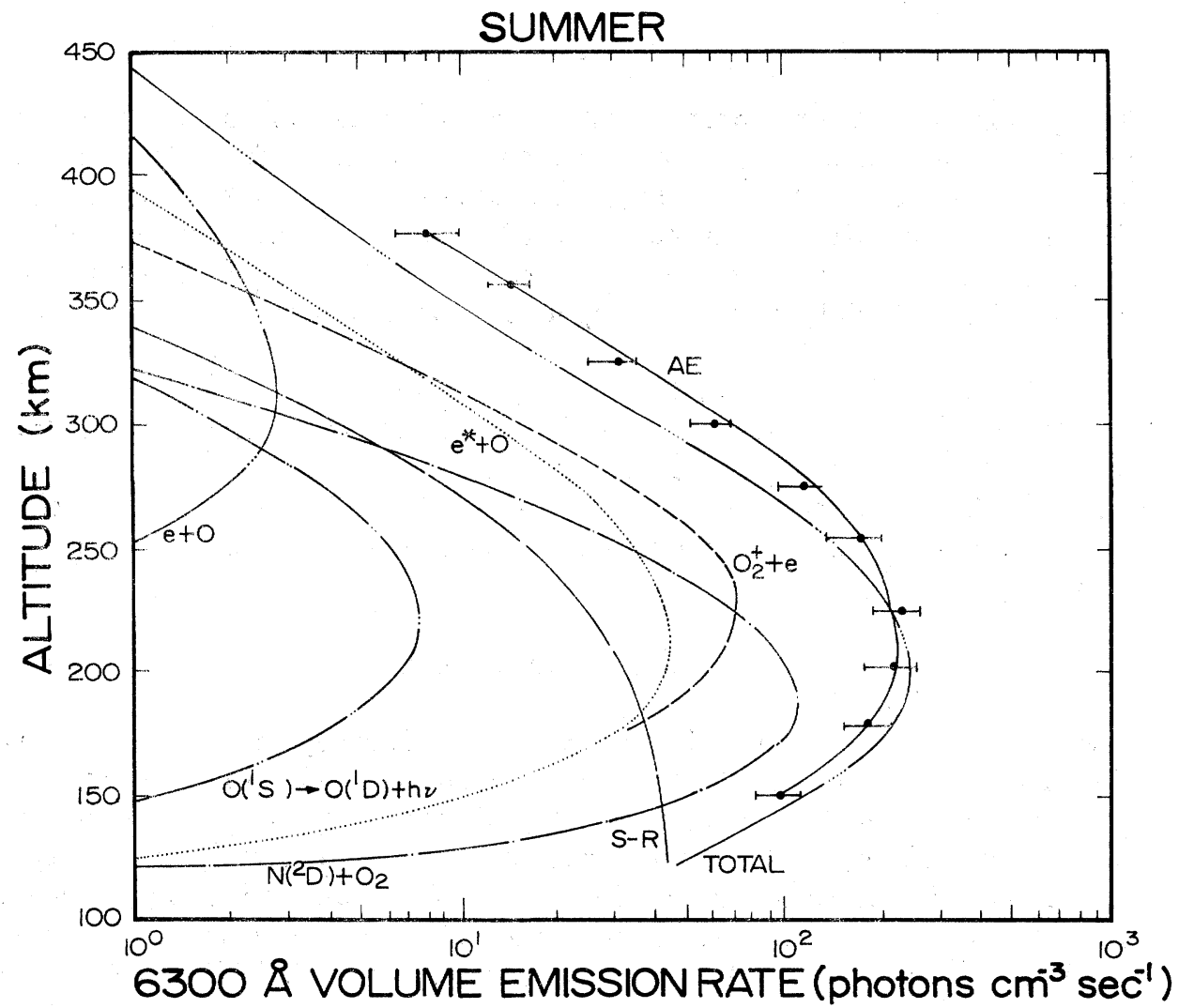

Fig. 4. Major sources of $\mathrm{O}\left({ }^{1} \mathrm{D}\right)$ showing the significance of the $\mathrm{N}\left({ }^{2} \mathrm{D}\right)+\mathrm{O}_{2}$ source. 


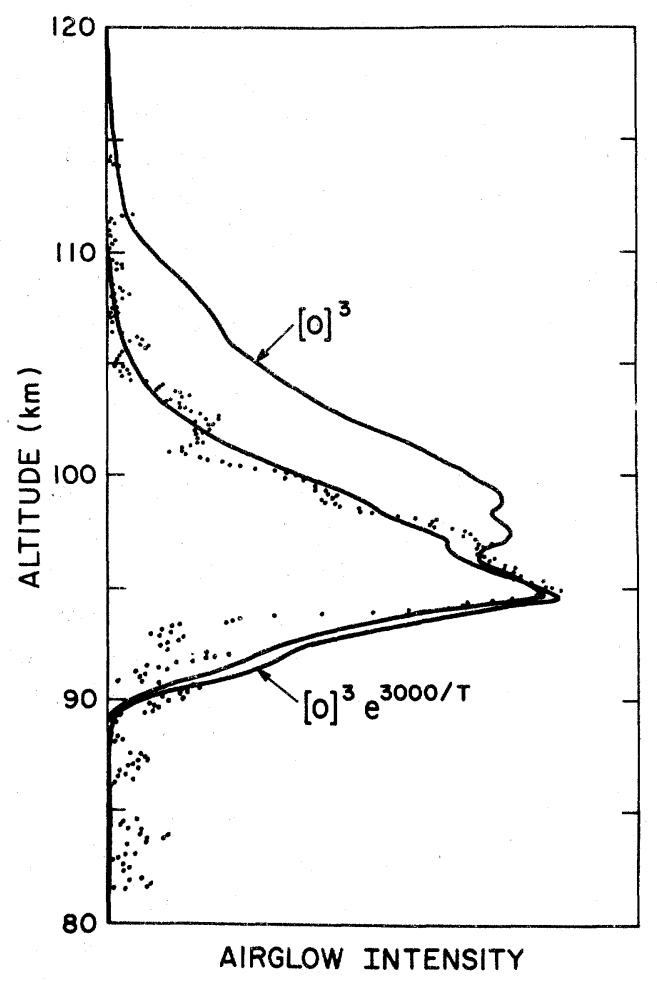

Fig. 5. Attempts to fit the Chapman mechanism to $5,577 \AA$ intensity data show that excess emission is predicted at high altitudes unless an unrealistic temperature dependence is added (from THOMAs, 1981).

From additional comparisons of models and observed profiles, he concluded that the quenching species could not be $\mathrm{O}\left({ }^{3} \mathrm{P}\right)$, and assumed that it must be $\mathrm{O}_{2}$.

THOMAS (1981) then considered the likely $\mathrm{O}_{2}$ state leading to $\mathrm{O}\left({ }^{1} \mathrm{~S}\right)$. This potentially could be $\mathrm{A}^{3} \sum_{\mathrm{u}}^{+}, \mathrm{C}^{3} \Delta_{\mathrm{u}}$ or $\mathrm{c}^{1} \sum_{\mathrm{u}}^{-}$. The $\mathrm{A}^{3} \sum_{\mathrm{u}}^{+}$state was rejected on height considerations and from considerations of the Venus night airglow. It was further concluded that the responsible remaining states must be vibrationally excited.

SLANGER and BLACK (1981) have subsequently reported that their earlier laboratory measurements which determined the predominant quencher of $\mathrm{O}\left({ }^{1} \mathrm{~S}\right)$ to be $\mathrm{O}\left({ }^{3} \mathrm{P}\right)$, were severely compromised by quenching by $\mathrm{O}_{2}\left(\mathrm{a}^{1} \Delta_{\mathrm{g}}\right)$, and that $\mathrm{O}\left({ }^{1} \mathrm{~S}\right)$ is in fact quenched by $\mathrm{O}_{2}\left(\mathrm{a}^{1} \Delta_{\mathrm{g}}\right)$.

\subsection{Photodissociation of $\mathrm{N}_{2}$}

An interesting problem has been identified regarding the photodissociation of $\mathrm{N}_{2}$ by extreme ultraviolet photons. ZIPF and MCLAUGHLIN (1978) found in a laboratory experiment in which $\mathrm{N}_{2}$ was bombarded by electrons, that there was strong emission of radiation from the $\mathrm{N}_{2}\left(\mathrm{C}^{1} \sum\right)$ state. However, in the aurora, there is a definite absence of radiation in the $800 \AA$ to $1,000 \AA$ wavelength range. This leads to the possibility that the radiation is resonantly entrapped by $\mathrm{N}_{2}$. If this 
should be the case, there is the distinct possibility that the $\mathrm{N}_{2}$ molecules would predissociate into $\mathrm{N}$ atoms.

RICHARDS et al. (1981) have made an estimate of what the impact would be on the odd nitrogen chemistry in the event that all of this EUV energy does indeed result in the predissociation of $\mathrm{N}_{2}$. They found that the result would be a significant increase in the production of $\mathrm{N}\left({ }^{2} \mathrm{D}\right)$ and $\mathrm{N}\left({ }^{4} \mathrm{~S}\right)$. Additional aspects of this would be that in order to compensate for the increased production of $\mathrm{N}\left({ }^{2} \mathrm{D}\right)$, previous determinations of the quenching of $\mathrm{N}\left({ }^{2} \mathrm{D}\right)$ by $\mathrm{O}$ would have to be increased by about $50 \%$ to $6 \times 10^{-13} \mathrm{~cm}^{3} \mathrm{sec}^{-1}$.

\subsection{Photoelectrons}

Over the past several years a controversy has existed in the area of the photoelectron flux spectrum and its absolute magnitude. This controversy has encompassed both measured and theoretically computed flux spectra. In the initial phase of the Atmosphere Explorer results, the situation was further aggravated by the fact that the data on one satellite differed from the data on another satellite. This was subsequently resolved by the identification of a shielding problem on one of the satellites in question. The situation then appeared to be one in which the various theories were in general agreement, but that the measured fluxes were larger by a factor of 2 in the 10 to $30 \mathrm{eV}$ range.

RICHARDS and TORR (1981) have recently conducted a detailed investigation into these aspects and found that things were not quite what they might at first have seemed to be. To begin with, various cross-sections are in existence. Cross-sections used in earlier models are smaller than more recent determinations now available by factors of up to 2 . A problem is that the various theories which are believed to agree and for which the results have been published either do not specify which crosssections were used or else have used the very different cross-sections. In the latter case, one would not have expected the inter-model agreement that resulted.

RICHARDS and TORR (1982) have since carried this study further. They have inverted the equations to solve for the total inelastic cross-section using measured fluxes. Conditions can be found under which at certain energies the cross-sections are dominated by a single process (e.g. $\left.\mathrm{O}\left({ }^{1} \mathrm{D}\right)\right)$. At these points the values determined in this way are in excellent agreement with the prevailing cross-sections. A problem becomes evident, however, at energies of $35 \mathrm{eV}$ and above. At these higher energies the cross sections are no longer consistent with the measured fluxes. It is at these higher energies between $35 \mathrm{eV}$ and $60 \mathrm{eV}$, however, that there is confidence in available cross-sections, implying that the AE measurements may be problematical in this energy range. It is not clear whether the problems may lie with the solar EUV or the photoelectron measurements.

\subsection{Thermospheric $\mathrm{O}_{2}$ and the $\mathrm{O}_{2}^{+}$photochemistry}

A major obstacle in many thermospheric chemistry studies has been the lack of direct measurements of $\mathrm{O}_{2}$. Even the most current models of the neutral atmosphere use $\mathrm{O}_{2}$ concentrations computed from outdated $\mathrm{O}_{2}^{+}$photochemistry. The open source mass spectrometer on the Atmosphere Explorer satellites did have the capability to measure $\mathrm{O}_{2}$ concentrations. The data reduction process, however, was 
rather laborious and it is only fairly recently that a measurement database has been available to permit a comparison against the model values. The results of this comparison are shown in Fig. 7 (TORR et al. 1982). Basically the agreement was found to be good at concentrations of $\sim 5 \times 10^{7} \mathrm{~cm}^{3}$ (corresponding to $\sim 220 \mathrm{~km}$ in altitude). However, for higher concentrations near $10^{10} \mathrm{~cm}^{3}$ (or lower altitudes) the model values were found to be significantly lower than the measurements. ToRR et al. (1982) have assessed the general impact of this difference on the thermospheric photochemistry, and conclude that it is mainly the odd nitrogen species which are impacted.

Because of the lack of direct measurements of the $\mathrm{O}_{2}$ concentration, an aspect of the thermospheric chemistry that has been neglected is the molecular ion $\mathrm{O}_{2}^{+}$. In a recent study (TORR and TORR, 1982) a comparison was made between the laboratory determination of the dissociative recombination rate coefficient of $\mathrm{O}_{2}^{+}$ with electrons, and that determined from the Atmosphere Explorer database. The results are shown in Fig. 8 and indicate a major discrepancy between the two. TORR and TORR (1982) interpreted this to be indicative of a problem in the understanding of the $\mathrm{O}_{2}^{+}$photochemical processes (and not in the dissociative recombination rate coefficient).

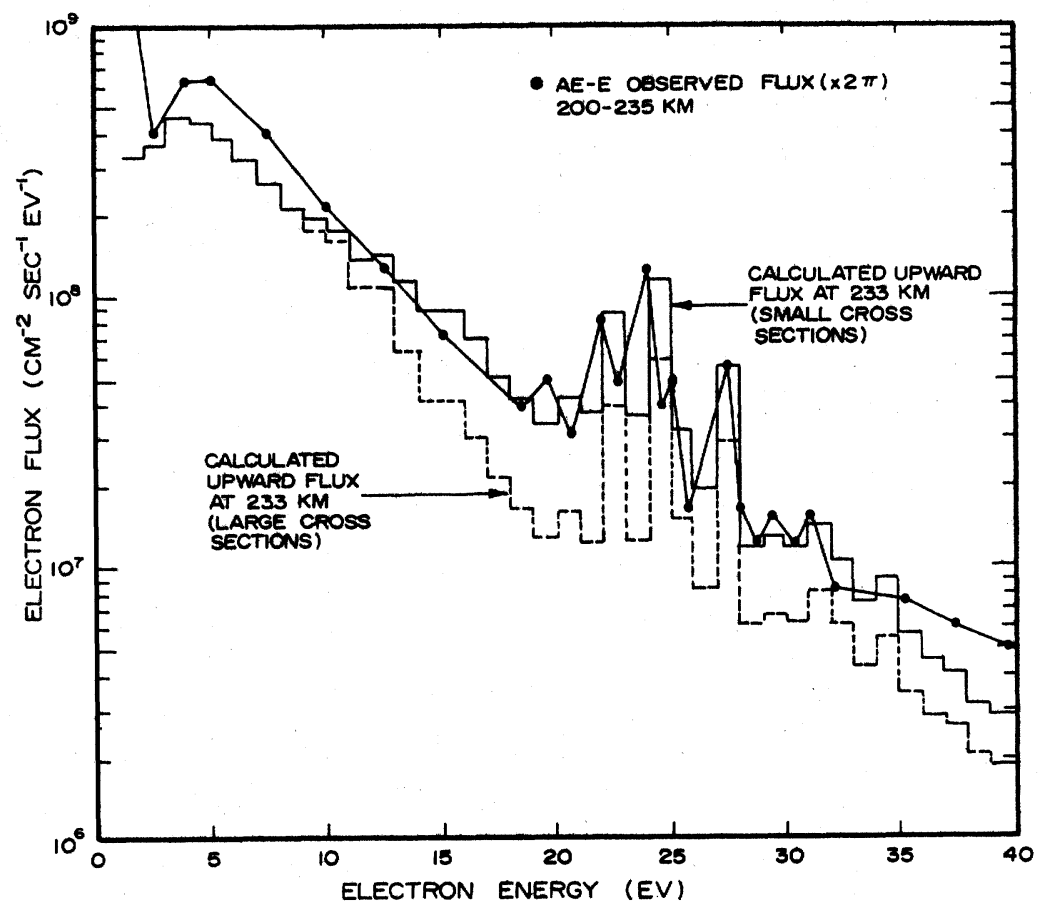

Fig. 6. Calculated upward moving photoelectron fluxes at $233 \mathrm{~km}$; with small cross-sections (full line), large cross-sections (broken line). The full circles are the AE-E measured photoelectron fluxes between $235-260 \mathrm{~km}$ multiplied by $2 \pi$ (from RICHARDS and TORR, 1981). 


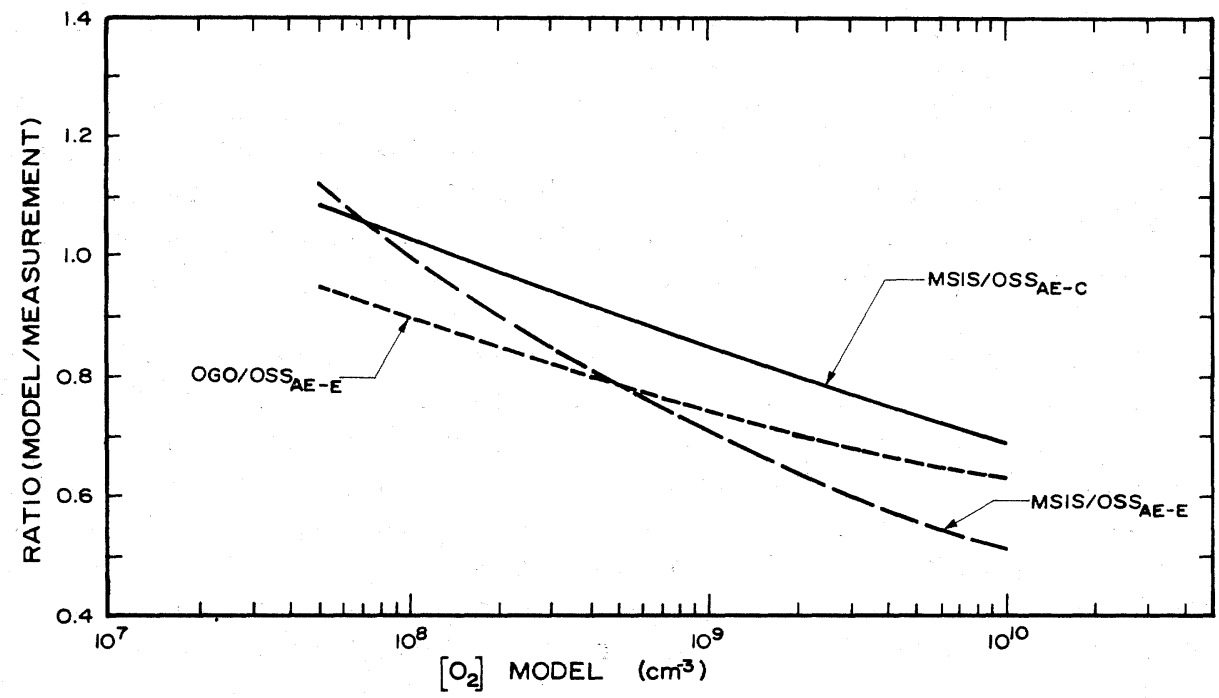

Fig. 7. Comparison of measured $\mathrm{O}_{2}$ concentrations with the concentrations predicted by the MSIS and OGO models (from ToRR et al., 1982).

A few months prior to this study it might have been concluded that the results were indicative of the presence of vibrationally excited $\mathrm{O}_{2}^{+}$. However, ZIPF (1980) found in the laboratory that the recombination rate of $\mathrm{O}_{2}^{+}$does not depend on vibrational excitation. Furthermore, BATES and ZIPF (1981) have concluded that $\mathrm{O}_{2}^{+}$(vib) will be too efficiently quenched by $\mathrm{O}$ for $\mathrm{O}_{2}^{+}$(vib) to be present in the thermosphere.

The problem appears to be associated with the $\mathrm{N}^{+}$source of $\mathrm{O}_{2}^{+}$and it is possible that the products of this reaction tend to be in a form that does not recombine as $\mathrm{O}_{2}^{+}$.

\subsection{The $2145 \AA$ mystery feature}

Several observations have been made over the years of a strong auroral feature at $2,145 \AA$. Initial identifications of the feature being $\mathrm{NO}_{\gamma}$ emission were dispelled and Dick (1978) suggested that the feature was due to the $\mathrm{N}^{+}\left({ }^{5} \mathrm{~S}\right)$ metastable ion. ERDMAN et al. (1981) attempted a measurement of the lifetime of the $\mathrm{N}^{+}\left({ }^{5} \mathrm{~S}\right)$ ion in a laboratory experiment. They determined the lifetime to be short (microsecond) and concluded that the emission could thus not be due to electron dissociationexcitation of $\mathrm{N}_{2}$. The theoretical radiative lifetime for $\mathrm{N}^{+}\left({ }^{5} \mathrm{~S}\right)$ is about $5 \mathrm{~ms}$ and this has been confirmed by a recent measurement by KNIGHT (1982). On this basis VICTOR and DALGARNo (1982) argued that the auroral feature is indeed the $\mathrm{N}^{+}\left({ }^{5} \mathrm{~S}\right)$ doublet at 2,143.6 $\AA$ and $2,139.7 \AA$, and that photoionization would produce this emission in the dayglow. Subsequently, BARTH and STEELE (1982) observed the feature in the dayglow, but at intensities only $20 \%$ of those predicted by VICTOR and DALGARNO (1982). 


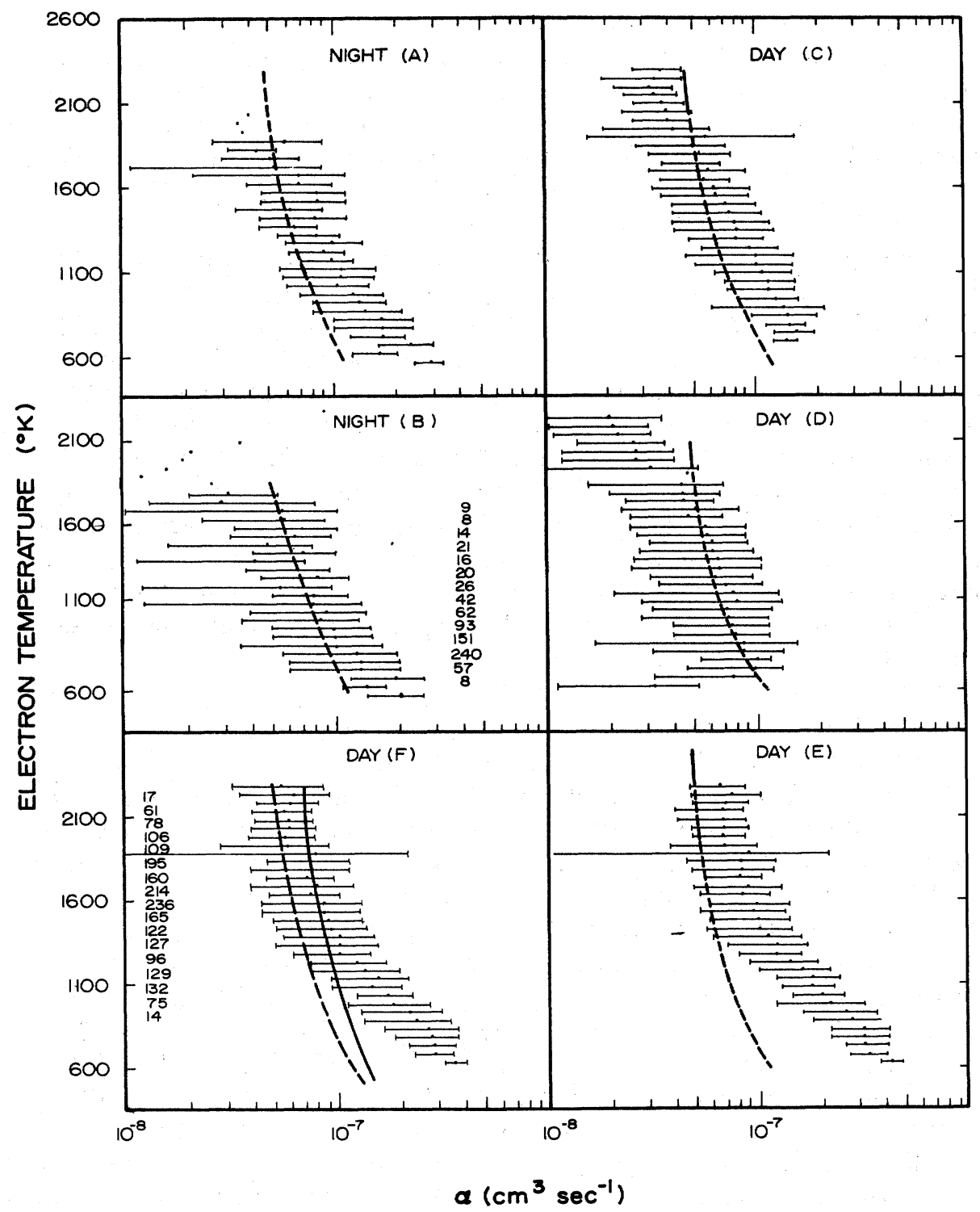

Fig. 8. Illustration of a significant problem in the understanding of the $\mathrm{O}_{2}^{+}$photochemistry. The various graphs show the results for both day and night-time comparisons of the $\mathrm{O}_{2}^{+}$ dissociative recombination rate coefficient; where the dots with error bars represent the $\mathrm{AE}$ aeronomical determination and the dashed line is the laboratory result of Walls and Dunn (1974). Panel (f) shows a large discrepancy at low values of Te, which could be explained by an $\mathrm{O}_{2}^{+}$source dependent on Te (from TORR and TORR, 1981). 


\subsection{Magnetic co-ordinate neutral atmosphere model}

STEHLE et al. (1982a, b) have analyzed both OGO-6 and AE-C satellite measurements of neutral atmospheric concentrations in terms of magnetic coordinates. Such models are particularly appropriate to high latitudes, and show latitudinal/UT structure not evident in the geographical co-ordinate MSIS model.

\subsection{Nocturnal photoionization rates}

Several years ago, STROBEL et al. (1974) evaluated possible nocturnal radiative ionization sources including HI Ly- $\alpha(1,216 \AA), \mathrm{Ly}-\beta(1,026 \AA)$, HeI $584 \AA$, and HeII $304 \AA$. They concluded that the nocturnal $E$ - and lower $F$-regions could be maintained by the Ly- $\alpha$ and Ly- $\beta$ radiation intensities. Subsequently, Balmer $\alpha$ airglow measurements by LEVASSEUR-REGOURD et al. (1976) required that the Ly- $\beta$ intensities previously used by STROBEL et al. (1974) be reduced by a factor of four. In the light of this change, STrobel et al. (1980) have re-evaluated the nocturnal sources and conclude that stellar continuum radiation in the spectral interval $911-1,026 \AA$ and resonance scattering of solar $\mathrm{Ly}-\beta$ into the night sector are the most important nocturnal sources in the $E$-region. These two sources are capable of maintaining electron densities of $(1-4) \times 10^{3} \mathrm{~cm}^{-3}$. They further found that in the $F$-region, the major source in the equatorial ionosphere is $910 \AA$ radiation from $\mathrm{O}^{+}$ recombination.

\subsection{Solar fluxes}

\subsubsection{Extreme ultraviolet fluxes (shortward of 1,027 $\AA$ )}

The variation of the EUV solar fluxes over the first half of solar cycle 21, and the corresponding variation in the photoionization frequencies has remained much as it was at the time of the Canberra meeting (ToRR et al., 1979) with some updates to the AE-E solar flux spectrum in this region by HINTEREGGER et al. (1981a). The impact of these updates can be seen in the flux data shown in Tables 1 and 2 which we reproduce here from an unpublished paper by HINTEREGGER et al. (1981b). In Table 1 is shown a comparison of the earlier flux measurements for the July 1976 time period (F76REF) with the later update for this period (SC\#21REF). The latter now represents the current solar-minimum reference for cycle 21 . The earlier version was used in the computation of ionization frequencies by ToRR et al. (1979) and at the most important wavelength $(304 \AA)$ is approximately $20 \%$ higher than the updated fluxes. In Table 2 we show the updated fluxes for day 50 of 1979. If these are compared with the earlier Hinteregger fluxes (see TORR et al. 1979) it can be seen that the photon flux at $304 \AA$ decreases by about $30 \%$. We can therefore conclude that the ionization frequencies determined by TORR et al. (1979) will decrease by $15 \%$ to $30 \%$ from 1976 to 1979 when the revised fluxes are taken into consideration. New ionization frequencies are being computed and will be published separately.

\subsubsection{Far ultraviolet fluxes (longward of 1,027 $\AA$ )}

The situation regarding solar flux measurements longward of Lyman- $\alpha$ has never been a tranquil one and this state has not changed since the last IAGA meeting.

A comparison of the flux measurements by various groups has been made by $P$. Simon (1981) and is shown in Fig. 9. The agreement is generally good with the 
Table 1. Ratio of revised (SC \#21REF) fluxes for July 1976 period to earlier reference spectrum (F76REF).

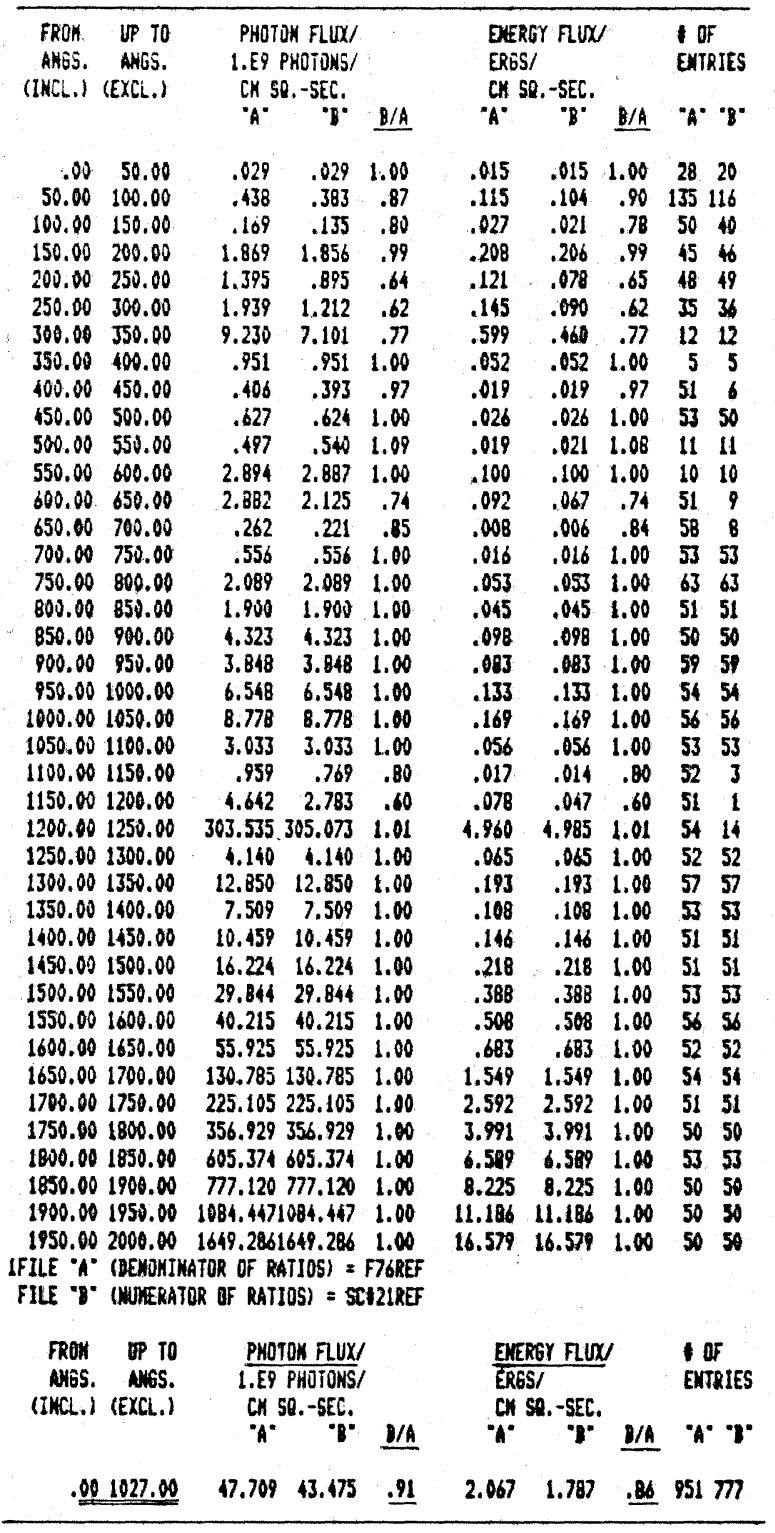


Table 2. Ratio of solar fluxes for early 1979 to July 1976.

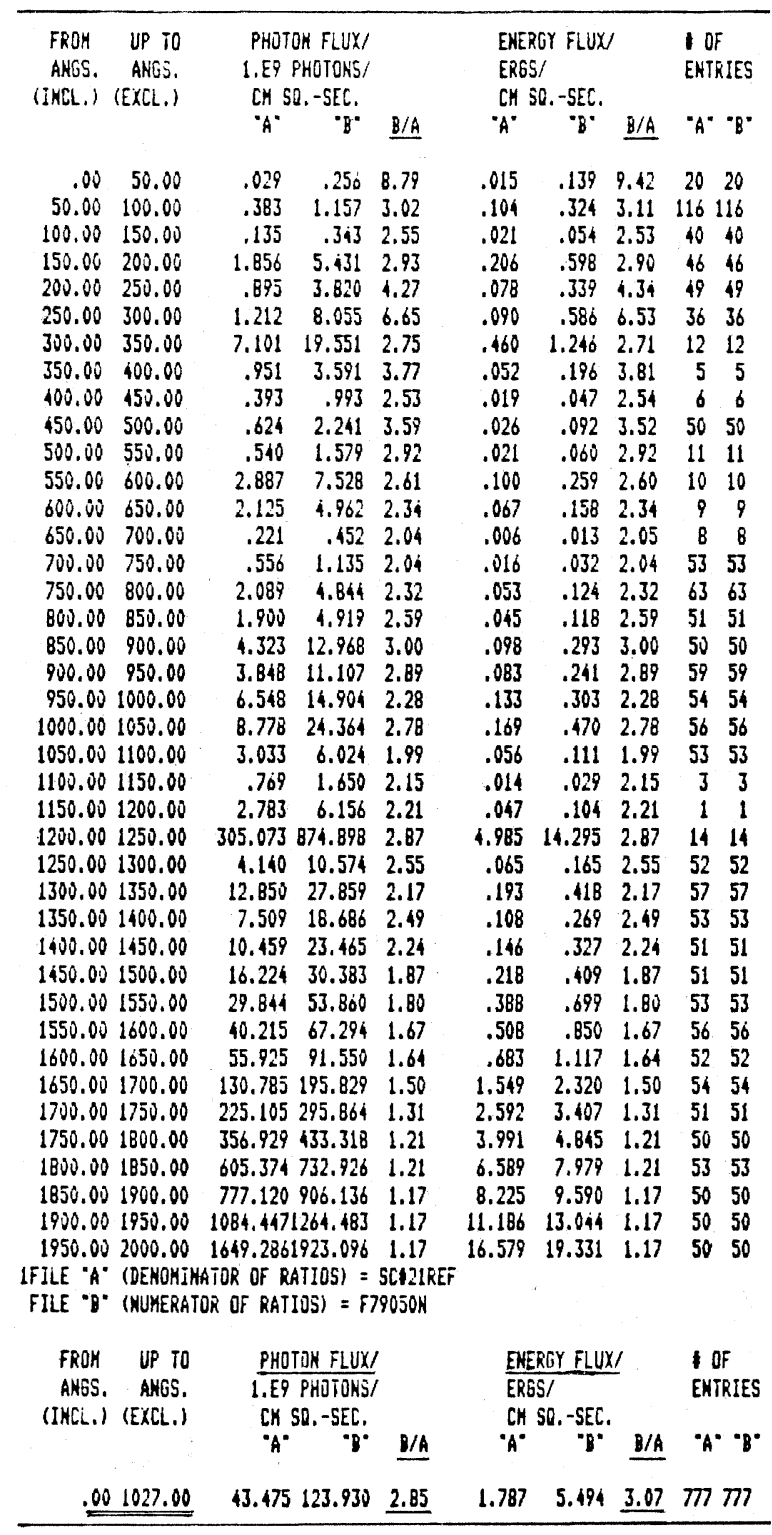




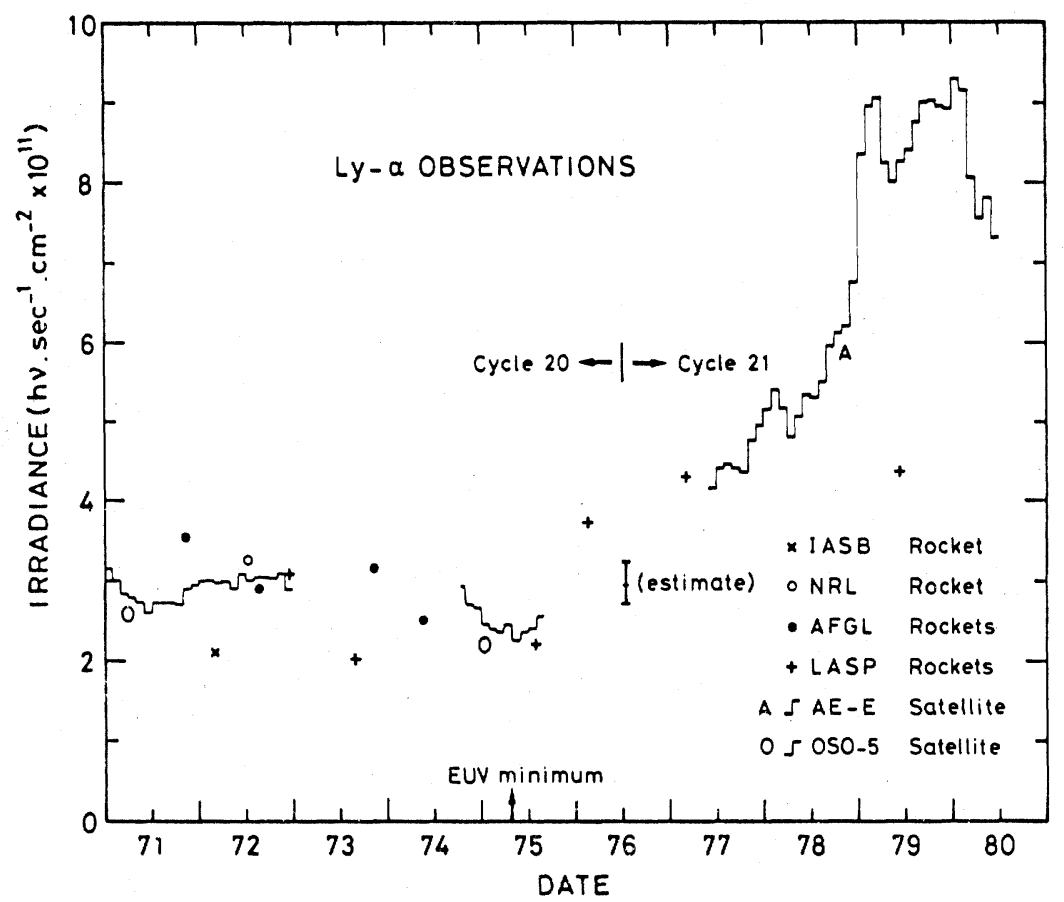

Fig. 9. Comparison of various solar flux measurements at Lyman- $\alpha$ (per courtesy P. Simon, 1981).

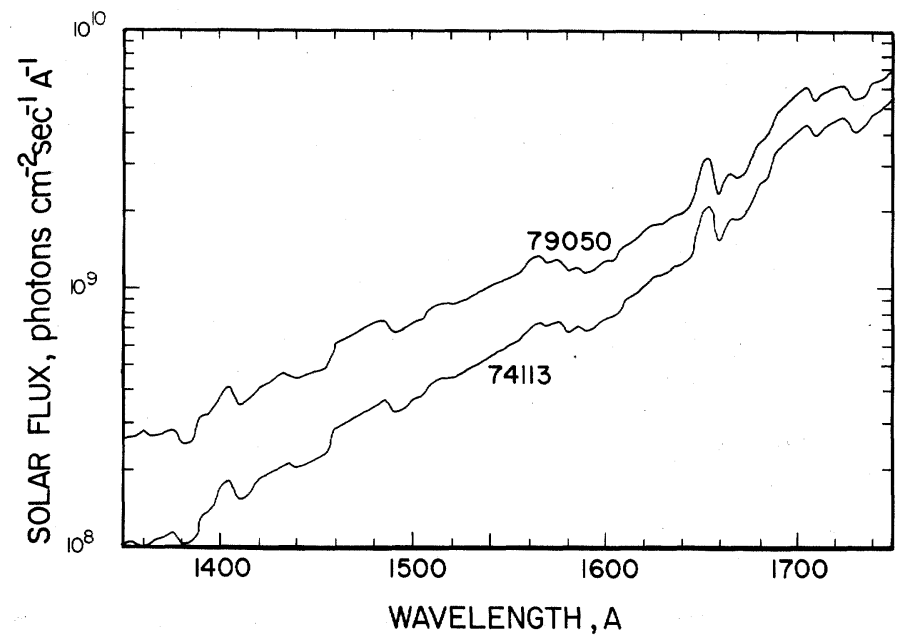

Fig. 10. Solar flux intensity in the wavelength range of the Schumann-Runge continuum for two days representative of solar minimum to solar maximum conditions respectively (from ToRR et al., 1980). 


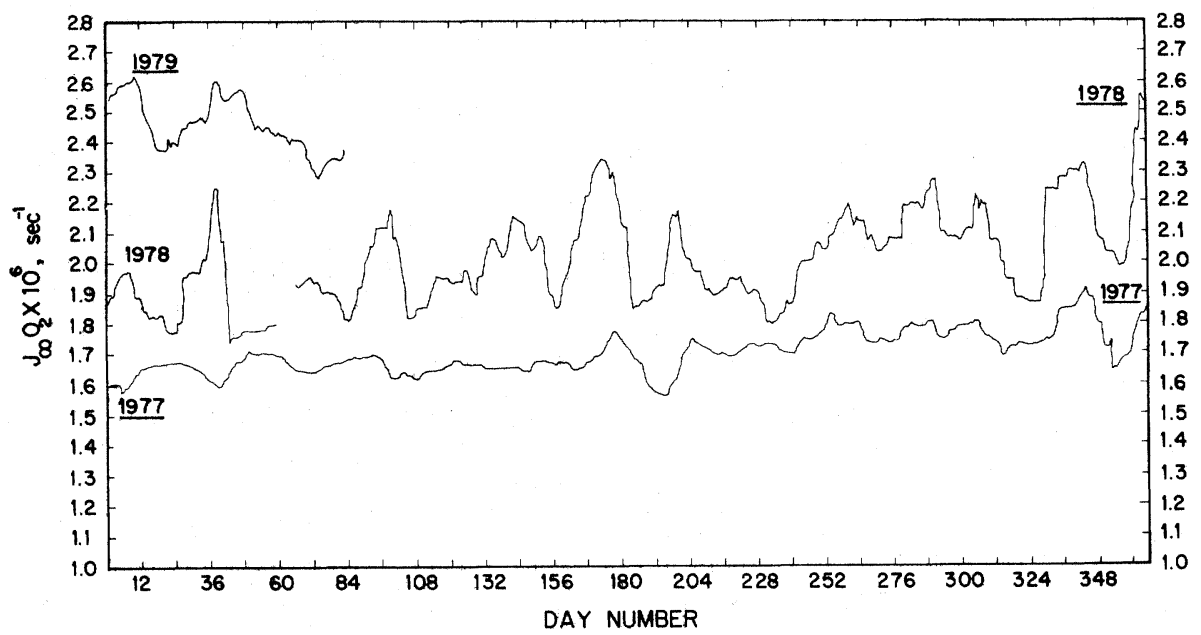

Fig. 11. Variation in the unattenuated photodissociation frequency for $\mathrm{O}_{2}$ in the SchumannRunge continuum for a wide range of solar conditions (from TORR et al., 1980).

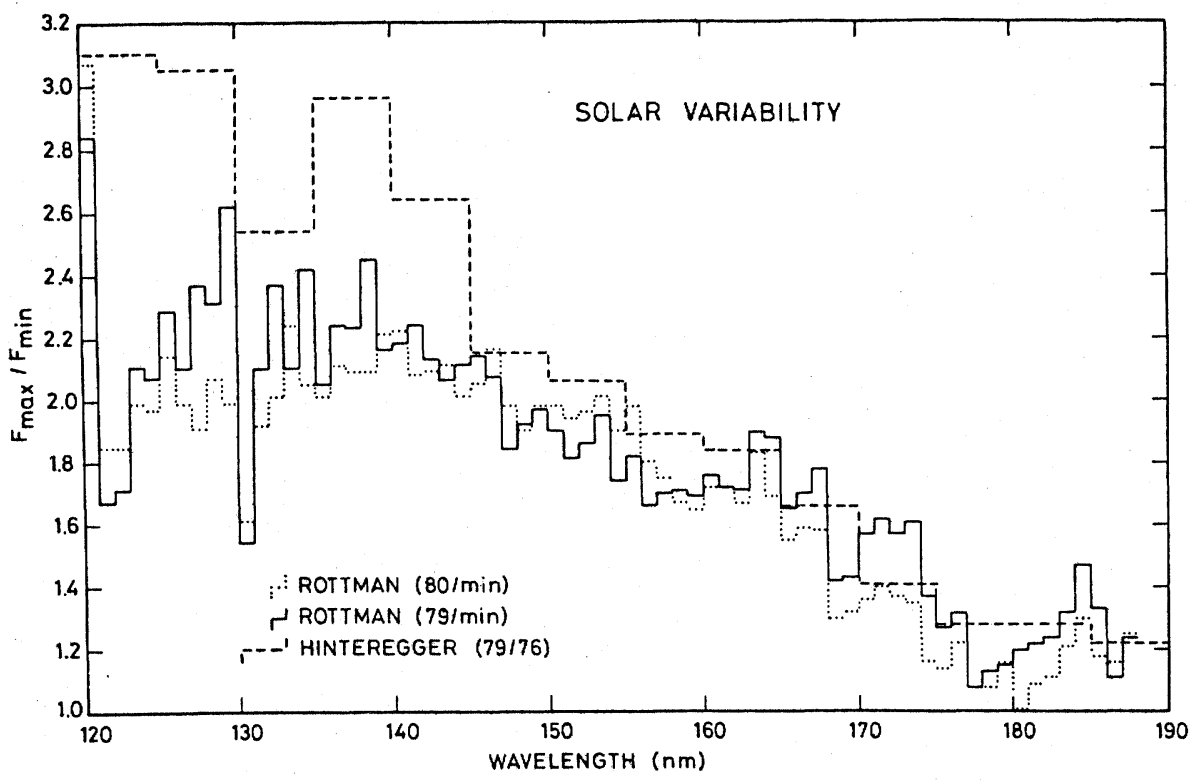

Fig. 12. Comparison of three sets of measurements of the solar minimum to solar maximum variation in flux over the $1,200 \AA$ to $1,900 \AA$ range (per courtesy P. Simon, 1981). 
exception of a rocket measurement by Rottman in 1978 and the Hinteregger Atmosphere Explorer data for that period.

In the last 18 months some very interesting progress has been made in understanding the temporal behaviour of solar fluxes in the wavelength range corresponding to absorption in the Schumann-Runge continuum (TORR et al., 1980). The Atmosphere Explorer observations have produced a database of almost daily measurements from 1977 to 1979 , with some observations in the 1974 to 1976 period. The variation over the solar cycle is shown in Fig. 10 and is almost a factor of 3 at $1,350 \AA$ and approximately $10 \%$ at the longer wavelengths. The effect of this on the photodissociation frequency for $\mathrm{O}_{2}$ is pronounced and is shown in Fig. 11. The variation in $J_{\infty}\left(\mathrm{O}_{2}\right)$ is almost a factor of 2 and has a strong superimposed 27 day variation.

A compilation of comparisons of various measurements at longer wavelengths has been compiled by P. Simon (1981) and is shown here in Figs. 12 through 16.

\subsection{Thermospheric solar ultraviolet heating efficiency}

At the IAGA meeting in Canberra in 1979, the results were reported of a new determination of the ultraviolet heating efficiency of the thermosphere (TORR et al.,

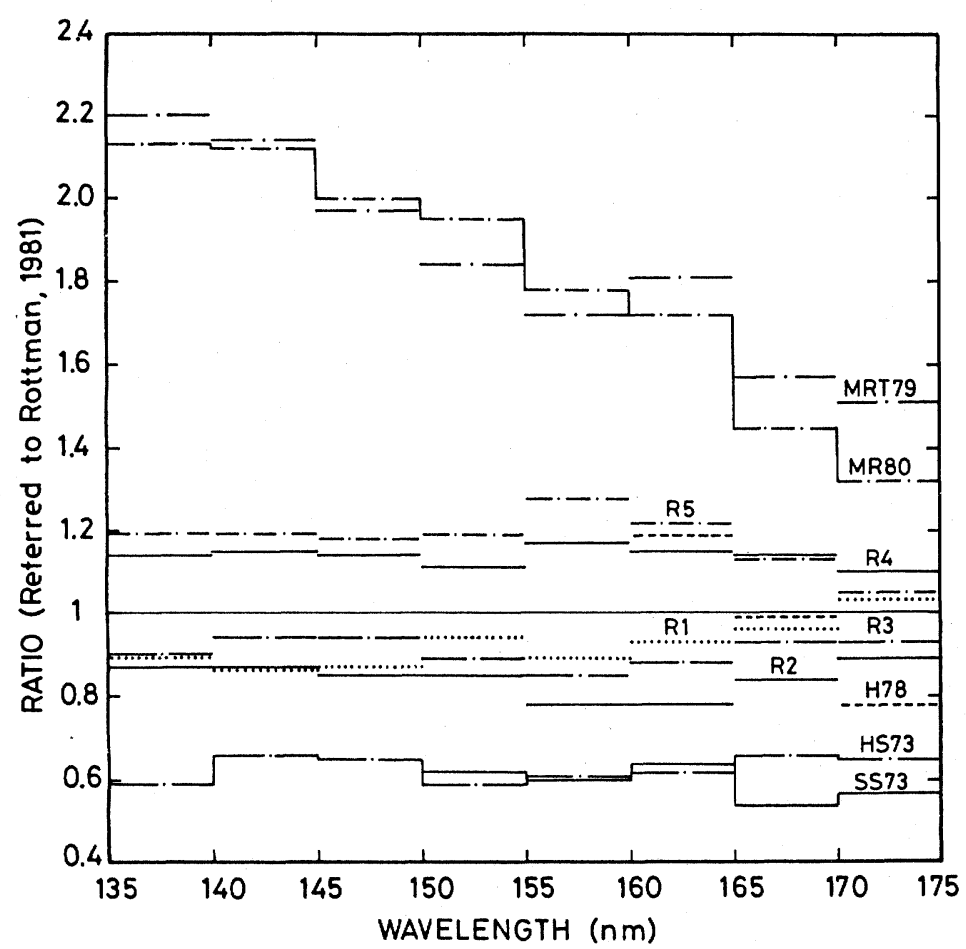

Fig. 13. Ratio of flux measurements made by various groups to that measured by Rottman over the $1,350 \AA$ to $1,750 \AA$ range (per courtesy P. Simon, 1981). 


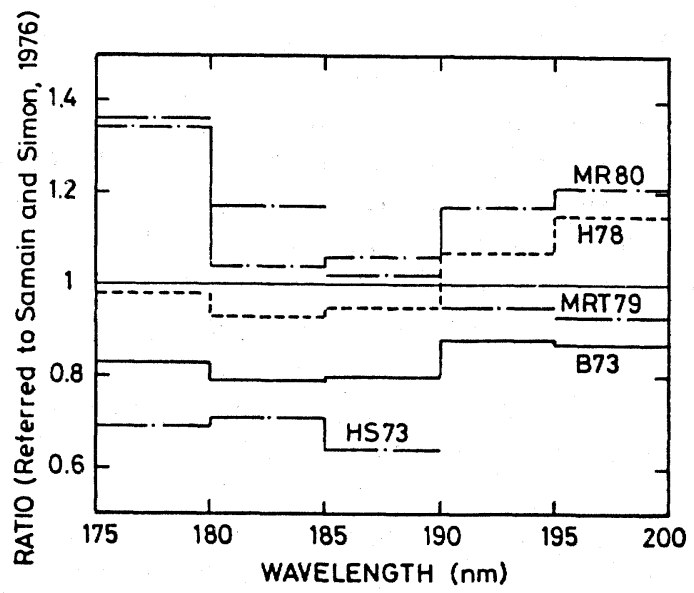

Fig. 14. Ratio of various flux measurements to those of Samain and Simon in the $1,750 \AA$ to $2,000 \AA$ range (per courtesy P. Simon, 1981).

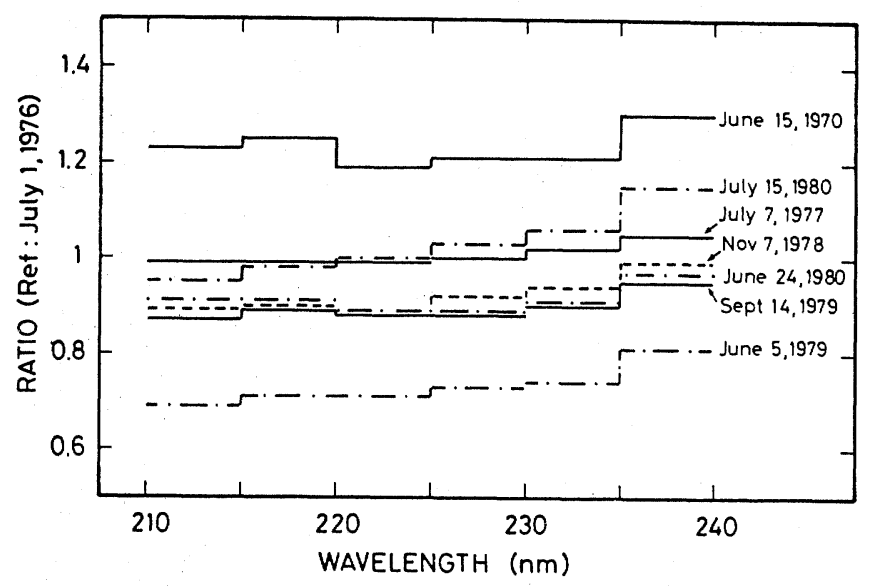

Fig. 15. Ratio of flux measurements on different days to those on July 1,1976 , (over the $2,100 \AA$ to. $2,400 \AA$ range) (per courtesy P. Simon, 1981). 


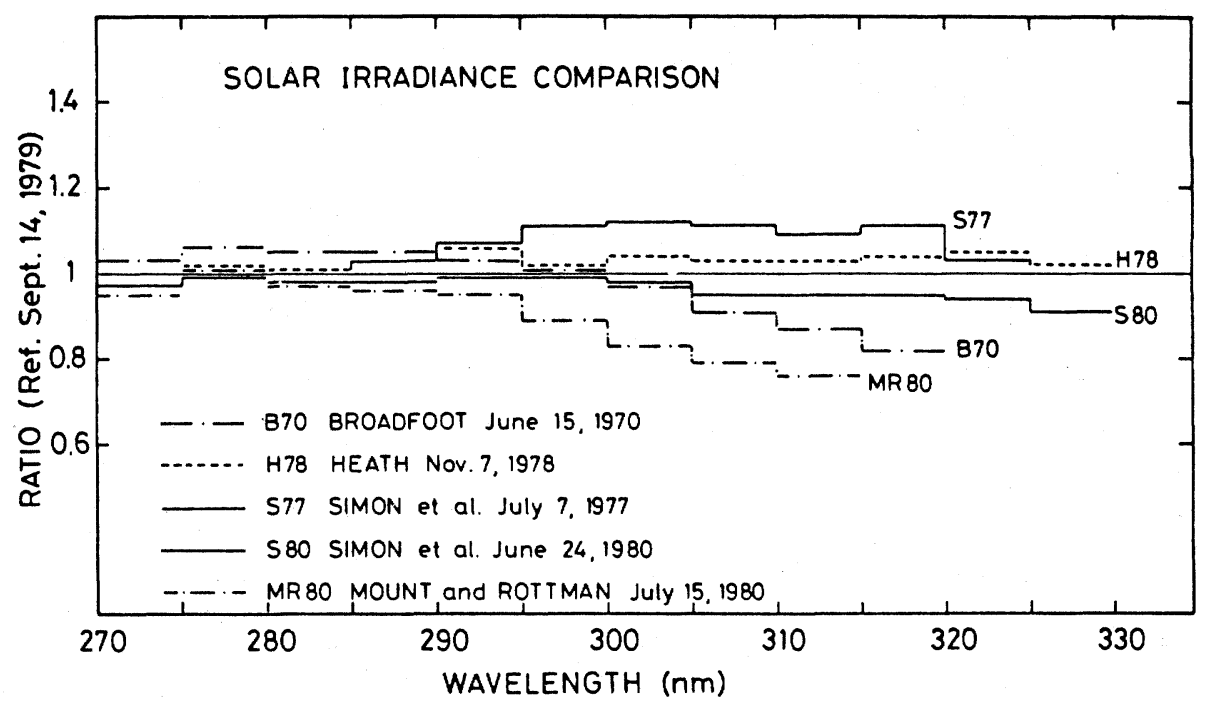

Fig. 16. Ratio of various solar flux measurements in the $2,700 \AA$ to $3,300 \AA$ wavelength range (per courtesy P. Simon, 1981).

1980). This study showed the heating efficiency to be a highly variable parameter, and significantly different from the almost constant value of $30 \%$ that had been previously assumed. The results at that time were from a steady state calculation. Since then the time dependent model has been solved and the results of this (shown in Fig. 17) confirm the rather dynamic character of the UV heating efficiency. The latent heat effect of the long lived species is clearly evident in the afternoon. Attention has recently been drawn to the thermospheric cooling mechanism provided by nitric oxide radiation at $5.3 \mu \mathrm{m}$ (KocKARDTS, 1980; RICHARDS et al., 1981). The impact of this cooling channel on the heating efficiency is illustrated in Fig. 18.

\section{Conclusions}

The progress in the general area of neutral and ion chemistry and solar fluxes over the period between the 1979 and 1981 IAGA meetings has been significant and most satisfactory. The field has reached a state of maturity in which many of the remaining issues are subtle and present fairly complex problems to be solved. Much needed at this point are good measurements of the $\mathrm{O}^{+}\left({ }^{2} \mathrm{D}\right)$ specie because of its pivotal role in the overall thermospheric chemistry. We also require careful and comprehensive studies of the vibrationally excited species. A major concern to the field is the absence of an orbiting extreme and far-ultraviolet solar flux monitor. Measurements in the foreseeable future will be restricted to short duration observations by a variety of instruments. In summary, the health of this field is good 


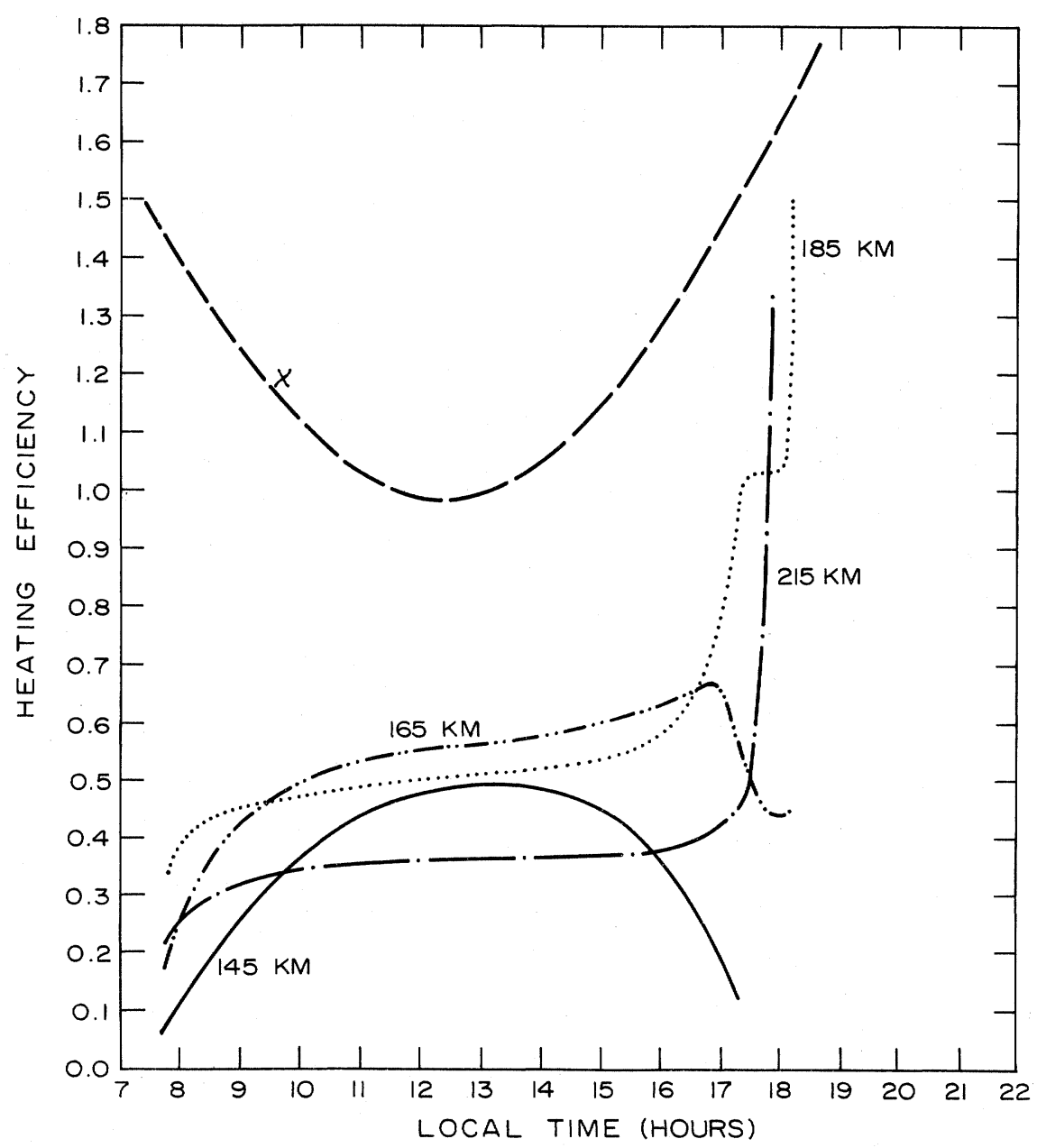

Fig. 17. Solar ultraviolet heating efficiency as a function of time at various altitudes for February 4, 1974.

and we can expect substantial developments by the time of the IAGA meeting in 1983.

We are most grateful to P. Simon who provided the material reproduced here as Figs. 12-16. This work was conducted under NASA grant NAGW-105 to the Utah State University. 


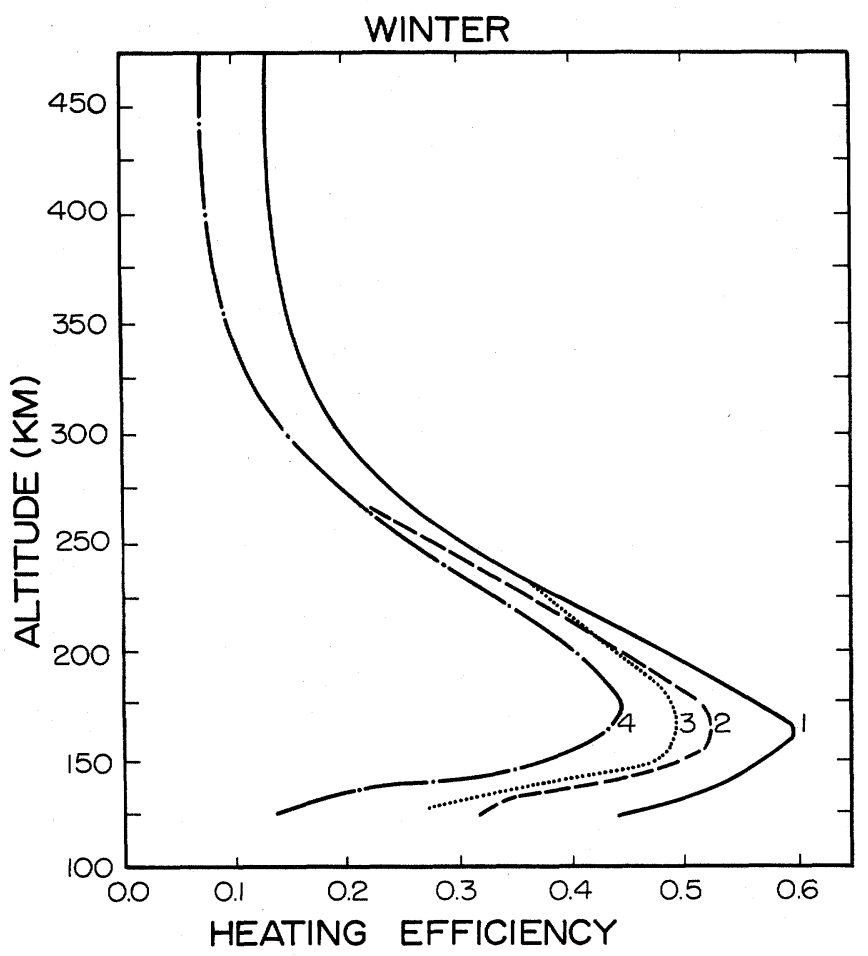

Fig. 18. Illustration of the impact of NO cooling at $5.3 \mu \mathrm{m}$ on the thermospheric heating efficiency (from RicHARDS et al., 1981). The figure shows the altitude variation of the heating efficiency in winter at solar minimum. Case 1 , no radiative cooling; case $2,63 \mu \mathrm{m}$ cooling but no $5.3 \mu \mathrm{m}$ cooling; case 3 , no $63 \mu \mathrm{m}$ cooling but $5.3 \mu \mathrm{m}$ cooling; and case 4 , both $63 \mu \mathrm{m}$ and $5.3 \mu \mathrm{m}$ cooling.

\section{REFERENCES}

Abdou, W. A., D. G. Torr, P. G. Richards, and M. R. TorR, The effect on thermospheric chemistry of a resonant charge exhange reaction involving vibrationally excited $\mathrm{N}_{2}^{+}$ions with atomic oxygen, $J$. Geophys. Res., 87, 6324, 1982.

AbDou, W. A., D. G. Torr, P. G. Richards, and M. R. TorR, Results of a comprehensive study of the photochemistry of $\mathrm{N}_{2}^{+}$in the ionosphere, submitted to J. Geophys. Res., 1983.

BARTh, C. A. and R. E. Steele, Rocket observation of the N II $2143 \AA$ dayglow, Geophys. Res. Lett., 9, $559,1982$.

Bates, D. R. and E. C. ZIPF, The $\mathrm{O}\left({ }^{1} \mathrm{~S}\right)$ quantum yield from $\mathrm{O}_{2}^{+}$dissociation recombination, planet. Space Sci., 28, 1081, 1981.

Breig, E. L., M. R. TORR, and D. C. KAYSER, Observations and photochemistry of $\mathrm{O}^{++}$in the daytime thermosphere, J. Geophys. Res., 1982 (in press).

Dick, K. A., The auroral $2150 \AA$ feature: A contribution from lines of singly ionized atomic nitrogen, Geophys. Res. Lett., 5, 273, 1978.

ERdman, P. W.,P. J. EsPY, and E. C. ZIPF, A laboratory study of the dissociative excitation of the $\mathrm{N}^{+}\left({ }^{5} \mathrm{~S}\right)$ state, Geophys. Res. Lett.,8, 1163, 1981.

Glosik, J., A. B. RAKshit, N. D. Twiddy, N. G. AdAMS, and D. Smith, Measurement of the rates of the 
reaction on ground and metastable excited states of $\mathrm{O}_{2}^{+}, \mathrm{NO}^{+}$and $\mathrm{O}^{+}$with atmospheric gases at thermal energy, J. Phys. B., 11, 3365, 1978.

HinteregGer, H. E., K. FukUi, and B. R. Gilson, Observational, reference and model data on solar EUV, from measurements on AE-E, Geophys. Res. Lett., 8, 1147, 1981a.

Hinteregger, H. E., K. Fukui, and B. R. Gilson, Solar EUV AE-E Satellite Observations and Aeronomical model representations for cycle 21, report distributed to Atmosphere Explorer Team, 30 March 1981b.

Johnsen, R. and M. A. Biond, Laboratory measurements of the $\mathrm{O}^{+}\left({ }^{2} \mathrm{D}\right)+\mathrm{N}_{2}$ and $\mathrm{O}^{+}\left({ }^{2} \mathrm{D}\right)+\mathrm{O}_{2}$ reaction rate coefficients and their ionospheric implications, Geophys. Res. Lett., 7, 401, 1980.

KNight, R. D., Radiative lifetime of the ${ }^{5} \mathrm{~S}_{2}$ metastable state of $\mathrm{N}^{+}$, Phys. Rev. Lett., 48, 792, 1982.

KockARDTs, G., Nitric oxide cooling in the terrestrial thermosphere, Geophys. Res. Lett., 7, 137, 1980.

Levasseur-Regourd, A. C., R. R. Meier, and B. A. Tinsley, Resolution of the discrepancy between Balmer-alpha emission rates, the solar Lyman-beta flux and geocoronal hydrogen models, $J$. Geophys. Res., 81, 5587, 1976.

LINK, R., J. R. MCCONNELl, and G. G. SHEPHERD, A self-consistent evaluation of the rate constants for the production of the OI $6300 \AA$ airglow, Planet. Space Sci., 29, 589, 1981.

Richards, P. G. and D. G. TORR, Determination of total inelastic cross sections for electron impact on O and $\mathrm{N}_{2}$ that are compatible with ionospheric measurements, submitted to J. Geophys. Res., 1982.

Richards, P. G., D. G. TorR, and M. R. TORR, Photodissociation of $\mathrm{N}_{2}$ : A significant source of thermospheric atomic nitrogen, J. Geophys. Res., 86, 1495, 1981.

Richards, P. G., M. R. TORR, and D. G. TorR, The seasonal effect of nitric oxide cooling on the thermospheric U. V. heat budget, Planet. Space. Sci., 30, 515, 1982.

Rowe, B. R., D. W. FAhey, F. C. FehSEnfeld, and D. L. Albritton, Rate constants for the reactions of metastable $\mathrm{O}^{++}$ions with $\mathrm{N}_{2}$ and $\mathrm{O}_{2}$ at collision energies 0.04 to $0.2 \mathrm{eV}$ and the mobilities of the ions at $300 \mathrm{~K}$, J. Chem. Phys., 73, 194, 1980.

Rusch, D. W., J. C. Gerard, and W. E. Sharp, The reaction of $\mathrm{N}\left({ }^{2} \mathrm{D}\right)$ with $\mathrm{O}_{2}$ as a source of $\mathrm{O}\left({ }^{1} \mathrm{D}\right)$ atoms in aurorae, Geophys. Res. Lett., 5, 1043, 1978.

Rutherford, J. A. and D. A. VRoom, Effect of metastable $\mathrm{O}^{+}\left({ }^{2} \mathrm{D}\right)$ on reactions of $\mathrm{O}^{+}$with nitrogen molecules, J. Chem. Phys., 55, 5622, 1971.

RUTHERFORD, J. A. and D. A. VROOM, The reaction of atomic oxygen with several atmospheric ions, $J$. Chem. Phys., 61, 2514, 1974

Slanger, T. G. and G. BlaCK, Quenching of $\mathrm{O}\left({ }^{1} \mathrm{~S}\right)$ by $\mathrm{O}_{2}\left(\mathrm{a}^{1} \Delta_{\mathrm{g}}\right)$, Geophys. Res. Lett., 8, 535, 1981.

Stebings, R. F., B. R. Turner, and J. A. Rutherford, Low-energy collisions between some atmospheric ions and neutral particles, J. Geophys. Res., 71, 771, 1966.

Stehle, C. G., J. S. Nisbet, and E. Bleuler, A global model of the neutral atmosphere in magnetic coordinates based on the OGO-6 data J. Geophys. Res., 87, 1615, 1982a.

Stehle, C. G., J. S. NisBet, and E. Bleuler, A global model of the neutral thermosphere in magnetic coordinates based on AE-C data, J. Geophys. Res., submitted, 1982b.

Strobel, D. F., T. R. Young, R. R. Meier, T. P. Coffey, and A. W. Ali, The night-time ionosphere: $E$ region and lower F-region, J. Geophys. Res., 79, 3171, 1974.

Strobel, D. F., C. B. Opal, and R. R. Meier, Photoionization rates in the night-time $E$ - and $F$-region ionosphere, Planet. Space Sci., 28, 1027, 1980.

Tномаs, R. J., Analyses of atomic oxygen, the green line and Herzberg band in the lower thermosphere, $J$. Geophys. Res., 86, 206, 1981.

Torr, D. G., P. G. Richards, M. R. Torr, and V. J. AbreU, Further quantification of the sources and sinks of thermospheric $\mathrm{O}\left({ }^{1} \mathrm{D}\right)$ atoms, Planet. Space Sci., 29, 595, 1981.

Torr, D. G., P. G. Richardson, and M. R. TorR, Ionospheric composition: The seasonal anomaly explained, in AGARD Conference Proceedings No. 295, The Physical Basis of the Ionosphere in the Solar-Terrestrial System, Hartford House, London, 1980.

Torr, M. R., D. G. Torr, R. A. Ong, and H. E. Hinteregger, Ionization frequencies for major thermospheric constituents as a function of Solar Cycle 21, Geophys. Res. Lett., 6, 771, 1979.

Torr, M. R., D. G. Torr, and H. E. Hinteregger, Solar flux variability in the Schumann-Runge continuum as a function of Solar Cycle 21, J. Geophys. Res., 85, 6063, 1980.

TORR, Marsha R., P. G. Richards, and D. G. TORR, A new determination of the ultraviolet heating efficiency of the thermosphere, J. Geophys. Res., 85, 6819, 1980. 
TORR, Marsha R. and D. G. Torr, The dissociative recombination of $\mathrm{O}_{2}^{+}$in the ionosphere, Planet. Space Sci., 29, 999, 1981.

TORR, Marsha R. and D. G. TORR, The role of metastable species in the thermosphere, Rev. of Geophys., 20, 91, 1982.

TORr, Marsha R., D. G. TORR, R. CARTER, and D. KAYSER, Thermospheric molecular oxygen, J. Geophys. Res., 87, 1727, 1982

VICtor, G. A. and A. Dalgarno, The $2145 \AA$ dayglow and the high latitude nitric oxide density, Geophys. Res. Lett., 9, 866, 1982.

ZIPF, E. C., A laboratory study on the dissociative recombination of vibrationally excited $\mathrm{O}_{2}^{+}$ions, $J$. Geophys. Res., 85, 4232, 1980.

ZIPF, E. C. and R. W. McLaughlin, On the dissociation of nitrogen by electron impact and by EUV photoabsorption, Planet. Space Sci., 26, 449, 1978. 